\title{
EFFECT OF POWDER RECYCLING ON THE FRACTURE BEHAVIOR OF ELECTRON BEAM MELTED ALLOY 718
}

\author{
H. Gruber, P. Karimi, E. Hryha, L. Nyborg
}

\begin{abstract}
Understanding the effect of powder feedstock alterations during multicycle additive manufacturing on the quality of built components is crucial to meet the requirements on critical parts for aerospace engine applications. In this study, powder recycling of Alloy 718 during electron beam melting was studied to understand its influence on fracture behavior of Charpy impact test bars. High resolution scanning electron microscopy was employed for fracture surface analysis on test bars produced from virgin and recycled powder. For all investigated samples, an intergranular type of fracture, initiated by non-metallic phases and bonding defects, was typically observed in the regions close to or within the contour zone. The fracture mode in the bulk of the samples was mainly moderately ductile dimple fracture. The results show a clear correlation between powder degradation during multi-cycle powder reuse and the amount of damage relevant defects observed on the fracture surfaces. In particular, samples produced from recycled powder show a significant amount of aluminum-rich oxide defects, originating from aluminum-rich oxide particulates on the surface of the recycled powder.
\end{abstract}

Keywords: additive manufacturing of Alloy 718 , electron beam melting, powder recycling, powder degradation, fractography of AM components

\section{INTRODUCTION}

Powder bed fusion additive manufacturing (AM) is a rapidly growing manufacturing method that has attracted increasing attention in both industry and academia during the last years. A key advantage of this process is the inherent ability of near-net shape production of structurally optimized, complex geometry components together with the potential to reduce material consumption. One such method is electron beam melting (EBM) in which the component is built by fusing together thin layers of metal powder using a focused electron beam.

Alloy 718 (commonly referred to as Inconel 718 or IN718 - Inconel 718 is a trade mark of the Special Metals Corporation group of companies) is an age-hardenable nickeliron base superalloy that offers an excellent combination of good mechanical properties, oxidation and corrosion resistance up to around $650^{\circ} \mathrm{C}$. It is one of the most widely used superalloys and is predominantly found in aeronautic engine components such as turbine and compressor discs, turbine shafts and compressor blades [1-3].

Hans Gruber, Eduard Hryha, Lars Nyborg: Department of Industrial and Materials Science, Division of Materials and Manufacture, Chalmers University of Technology, Gothenburg, SE-412 96, Sweden

Paria Karimi: Department of Engineering Science, Additive Manufacturing Group, University West, SE-46186 Trollhättan, Sweden 
The production route of aerospace components has traditionally involved extensive machining often resulting in low buy-to-fly ratios. Also, the high roomtemperature hardness of such alloys results in high tool wear and poor workpiece surface integrity when applying conventional, subtractive manufacturing methods. Therefore, due to its ease-of-fabrication capabilities and potential material cost savings, AM has been recognized by the aerospace industry as an attractive alternative production method [4-5]. However, components for such applications are exposed to an adverse set of mechanical, thermal and chemical loads resulting in strict quality control throughout the whole manufacturing chain from raw material to final product [6].

Even though additive manufacturing is capable of producing parts of equal or even superior mechanical performance compared to casting or forging, there is still a need for greater understanding regarding process stability and defect formation to ensure high resistance to, for example, crack initiation during cyclic loading [7].

Due to the relatively high cost of the metal powder feedstock used for AM, the permitted number of powder re-use times before risking a loss in the part performance has a significant influence on its cost-effectiveness. Studies have been performed to understand the importance of different physical and chemical powder characteristics on the process robustness and quality of fabricated parts and attempts have been made to assess the stability of the powder feedstock for use over extended time periods [5]. However, more knowledge is required to understand the effect of powder degradation on the final properties of the built components.

This work was done to study the fracture characteristics of EBM processed Alloy 718. Fracture surface analysis was performed to understand the effect of powder degradation on defect formation and fracture behavior of test samples produced from virgin and multi-cycle re-used powder.

\section{MATERIALS AND METHODS}

In the present study, EBM was used to fabricate standard Charpy V-notch (CVN) impact test bars from pre-alloyed Alloy 718 powder using an Arcam A2X EBM system located at University West, Trollhättan, Sweden. The powder feedstock material was commercial plasma-atomized powder provided by Arcam AB, Sweden. It had a powder size distribution of $45-105 \mu \mathrm{m}$ and a chemical composition resembling the nominal composition of Alloy 718 as presented in Table 1.

Tab.1. Chemical composition of the Alloy 718 powder.

\begin{tabular}{|l|l|l|l|l|l|l|l|l|l|l|l|l|l|l|l|}
\hline Element & $\mathrm{Ni}$ & $\mathrm{Cr}$ & $\mathrm{Fe}$ & $\mathrm{Nb}$ & $\mathrm{Mo}$ & $\mathrm{Ti}$ & $\mathrm{Al}$ & $\mathrm{Mn}$ & $\mathrm{C}$ & $\mathrm{Co}$ & $\mathrm{Ta}$ & $\mathrm{B}$ & $\mathrm{Si}$ & $\mathrm{P}$ & $\mathrm{S}$ \\
\hline wt.\% & 54.1 & 19.0 & 16.9 & 5.0 & 3.0 & 1.0 & 0.5 & 0.1 & 0.3 & 0.04 & $<0.01$ & 0.001 & 0.06 & 0.004 & $<0.001$ \\
\hline
\end{tabular}

The EBM process operates in a helium atmosphere at a partial vacuum level of $2 \mathrm{x}$ $10^{-3}$ mbar. During the whole process the complete powder bed is held at an elevated temperature (around $1000^{\circ} \mathrm{C}$ for Alloy 718 ). The part is built by alternating raking, sintering and melting of thin layers of metal particles. For each layer, a contour exposure is applied for consolidation along the component edges followed by a hatching exposure at the core. It should be noted that the differences in scanning strategies between contour and hatch region result in very different microstructures at the sample edges as compared to the bulk region [8]. After completion, the components are left to cool to a temperature below $100^{\circ} \mathrm{C}$ before they are removed from the process chamber. A more detailed description of the EBM process can be found in for example V. Sames et al. [9] or in H. Gruber et al. [10]. 
In total, the current study comprised 14 build cycles, spanning over a total build process time of around 500 hours, and initially involved $100 \mathrm{~kg}$ of virgin Alloy 718 powder that was loaded into the EBM machine before the start of cycle one. Hereafter, addition of fresh powder was kept as low as possible.

The CVN test samples with the dimension $11 \times 11 \times 60 \mathrm{~mm}$ were produced during each of cycle number 1, 6 and 14. Throughout the whole study, standard melt strategies and process parameters provided by the machine supplier were used for both contour and hatching exposure. The samples were built with the longitudinal axis parallel to the building direction. After EBM processing the samples were machined to the specified geometry as prescribed in ASTM standard E23-16b, illustrated in Fig.1. The notch was cut out using electrical discharge machining.

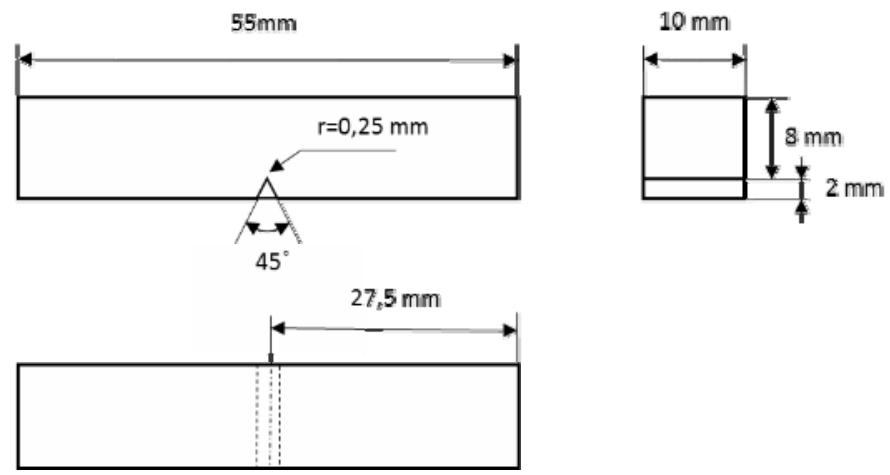

Fig.1. Charpy V-notch impact test sample geometry.

Between every build cycle the powder feedstock material was recovered according to the procedure specified by the machine manufacturer. Details on the powder recovery procedure can be found in for example Dehoff et al. [5] or in H. Gruber et al. [10]. For each of the build cycles, powder material from different positions within the building chamber was sampled for physical and chemical analysis. Detailed morphological analysis of the powder surface was performed using a Leo Gemini high resolution scanning electron microscope (HR SEM) equipped with an in-lens secondary electron detector. A solid state energy dispersive X-ray spectrometer (EDX) from Oxford Instruments (X-Max, Oxford Instruments Ltd., High Wycombe, UK) connected to the SEM was used for qualitative analysis of the phases present on the powder surface.

The CVN tests were performed on an Instron Wolpert PW30 impact tester with a capacity of 300 Joules. The test bars were tested and analyzed in as-built condition, without any subsequent heat treatment. Fracture surface analysis and metallography was done to study the fracture behavior and the presence of defects in test samples produced from powder feedstock material subjected to varying numbers of re-use cycles. Fracture surface analysis was performed using a Zeiss Discovery stereomicroscope supported by scanning electron microscopy and EDX for detailed analysis and micro-chemical analysis, respectively. 


\section{RESULTS AND DISCUSSION}

\section{Powder analysis}

High-resolution scanning electron microscopy of the virgin and recycled powder was done to detect alterations in the powder surface chemistry and morphology connected to multi-cycle powder re-use. Representative surface morphologies of virgin and recycled powder are shown in Figure 2 and 3, respectively. In its virgin state, the powder generally consists of mostly spherical particles with a relatively clean appearance. Even though observed on relatively rare occasions, the virgin powder contains non-metallic inclusions, mainly Ti-rich nitride particles, being around a few $\mu \mathrm{m}$ in size (see Figure 2b). In general, however, the virgin powder surface shows only little presence of secondary phases and surface contamination, even at very high magnifications. However, already after the first build cycles, nano-sized secondary phase particulates start to form on the powder surface and tend to grow with increasing number of re-use cycles. After 14 build cycles, a considerable portion of the powder surface is covered by such particulates, as shown in Figure 3a. Even though their small size does not allow for quantitative chemical analysis by EDX, the clear enrichment in aluminum and oxygen as compared to the matrix material (see Table 2) indicate them as Al-rich oxide particles. A more detailed analysis of the powder material from a selection of the performed build cycles can be found elsewhere $[10]$.
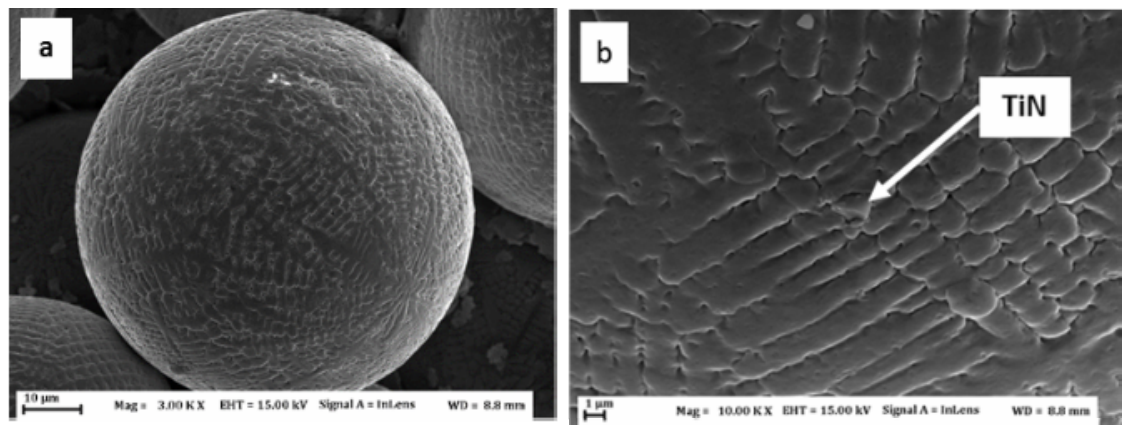

Fig.2. Surface morphology of the virgin powder.
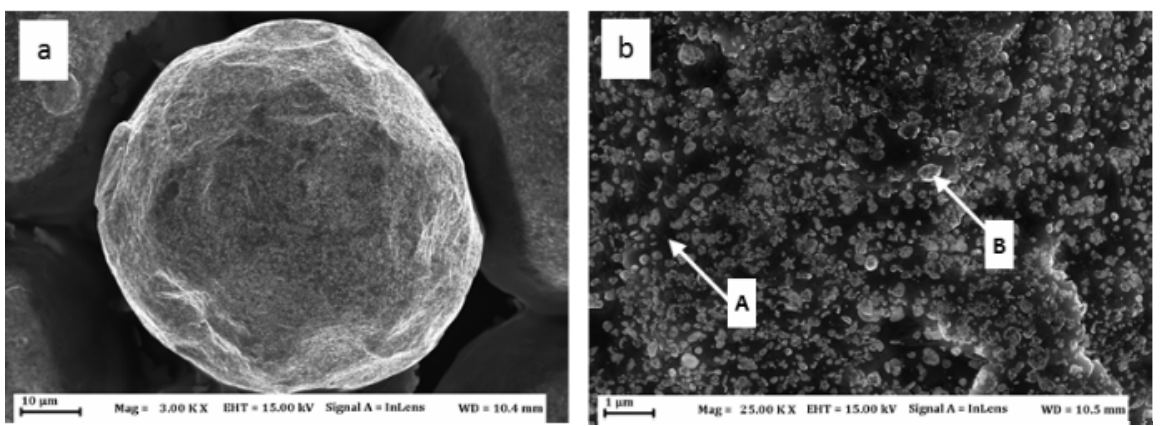

Fig.3. Surface morphology of the Alloy 718 powder after 14 re-use cycles. Corresponding EDX point analysis data are presented in Table 2. 
Tab.2. EDX analysis data corresponding to analysis points in Fig.3b.

\begin{tabular}{|c|c|c|c|c|c|c|c|c|c|c|}
\hline \multirow{2}{*}{ Location } & \multirow{2}{*}{ Structure } & \multicolumn{9}{|c|}{ Chemical composition } \\
\cline { 3 - 11 } & & & $\mathrm{Ni}$ & $\mathrm{Cr}$ & $\mathrm{Fe}$ & $\mathrm{Nb}$ & $\mathrm{Mo}$ & $\mathrm{Ti}$ & $\mathrm{Al}$ & $\mathrm{O}$ \\
\hline \multirow{2}{*}{$\mathrm{A}$} & Gamma & wt.\% & 52.5 & 19.4 & 19.0 & 4.2 & 3.0 & 1.2 & 0.7 & \\
& matrix & at.\% & 51.6 & 21.5 & 19.8 & 2.6 & 1.8 & 1.4 & 1.4 & - \\
\hline \multirow{2}{*}{$\mathrm{B}$} & Aluminum- & wt.\% & 36.7 & 15.3 & 14.5 & 3.6 & 2.0 & 1.5 & 13.2 & 13.2 \\
& rich oxide & at.\% & 24.2 & 11.4 & 10.1 & 1.5 & 0.8 & 1.2 & 18.9 & 31.9 \\
\hline
\end{tabular}

\section{Fracture surface analysis}

The fracture surface of a sample produced from virgin powder is shown in Fig.4a.

On a macroscopic level, all investigated fracture surfaces had a similar overall appearance. They all showed only minor lateral expansion, which is an indication of a relatively brittle fracture. The fracture surface can be divided into two distinct regions - the core or bulk region of the sample, where a hatch exposure was performed, and the around $1 \mathrm{~mm}$ wide region along the surface edges which corresponds to the contour region (around 1,5 mm before machining). Macroscopically, the whole fracture surface is highly irregular and contains numerous ridges and depressions. Un-melted metal particles and secondary phases such as oxides were often observed in these sites, indicating damage initiation and crack front propagation along defect-containing weak interfaces. Similar observations have been done by, for example Deng et al. [8]. However, in that case presence of carbides and porosity was identified as a reason for the weak interfaces. At higher magnifications, as in Figure 5 and 6 , it is realized that a large part of the areas close to and within the contour region consists of large, strikingly flat areas, partly covered with oxide films. As a consequence of the considerable amount of oxide phase on the surface of the re-cycled powder, the oxide covered areas in the samples produced from re-cycled powder (Fig.6) are significantly larger, as compared to the samples produced from virgin powder (Fig.5). Also in these areas, presence of un-melted powder particles and non-metallic phases indicate that many of these defects originate from both insufficient melting (lack of fusion) and/or weak bonding between non-metallic phases (oxide and nitride) and matrix material. Also in metallographic samples, larger sized defects preferentially located to the sample edges identify a high defect density close to or within the contour region, as shown in Fig.4b. In both cases, secondary phase particles such as Al-rich oxide and Ti-rich nitride are often spotted in the oxide-covered areas, as can be seen in Fig.5b. Corresponding qualitative chemical analysis measured by EDX analysis is presented in Table 3. The macroscopically rough topography in combination with the large fraction of defects suggests an intergranular type of failure, through crack propagation along weak interfaces, to be the main fracture mechanism close to or within the contour region. Due to the brittle nature evidenced by the widespread defect areas in this region, its contribution to the overall material toughness is most likely very small. 

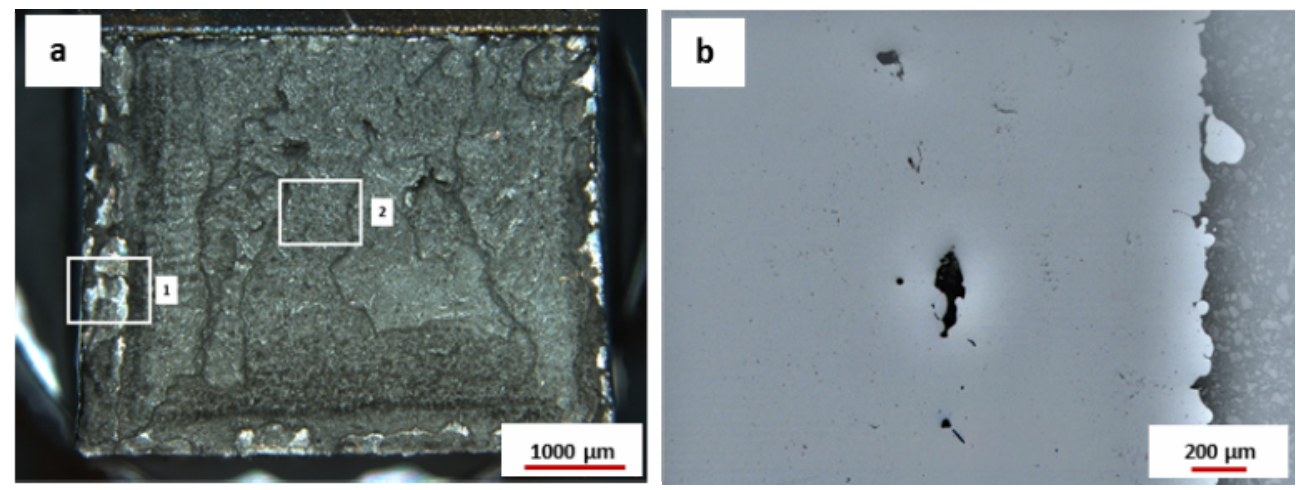

Fig.4. (a) Fracture surface of a CVN test sample produced from virgin powder. Denoted regions are further presented in Figs. 5 and 7, respectively. (b) Metallographic cross section of a sample produced from virgin powder showing large defects along sample edges.
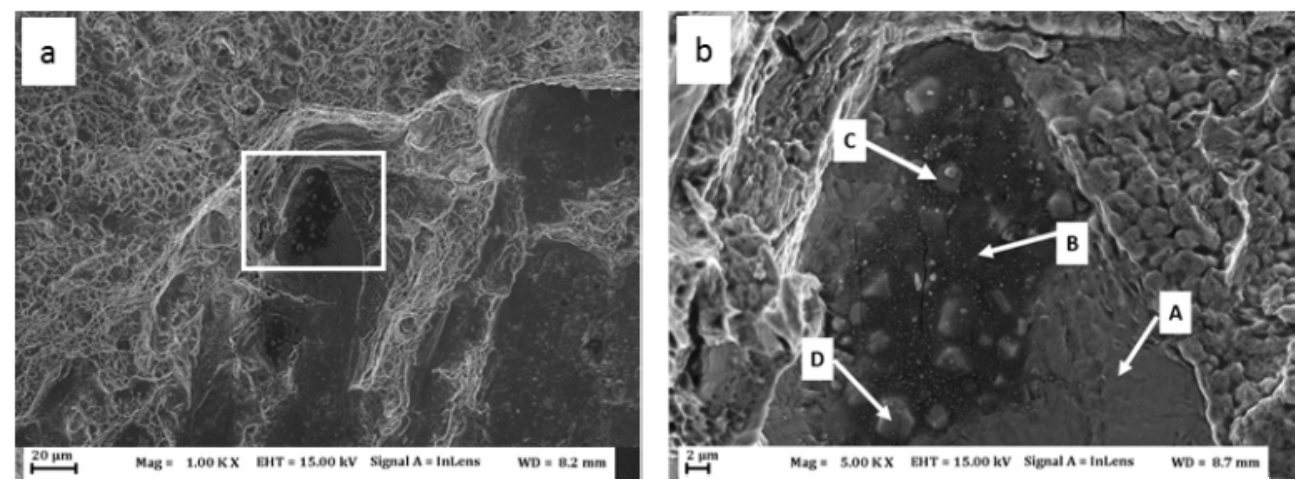

Fig.5. (a) Contour region on the fracture surface of a CVN test sample produced from virgin powder. (b) Higher magnification of denoted region showing oxide covered area with the presence of non-metallic particles. Corresponding EDX analysis data are presented in Tab.3.

Table 3. EDX analysis data from areas in Fig.5b.

\begin{tabular}{|c|c|c|c|c|c|c|c|c|c|c|c|}
\hline \multirow{2}{*}{ Location } & \multirow{2}{*}{ Structure } & & \multicolumn{9}{|c|}{ Chemical composition } \\
\hline & & & $\mathrm{Ni}$ & $\mathrm{Cr}$ & $\mathrm{Fe}$ & $\mathrm{Nb}$ & Mo & $\mathrm{Ti}$ & $\mathrm{Al}$ & $\mathrm{N}$ & $\mathrm{O}$ \\
\hline \multirow{2}{*}{ A } & Gamma & wt. $\%$ & 51.6 & 18.7 & 19.2 & 5.3 & 3.1 & 1.3 & 0.8 & \multirow{2}{*}{ - } & \\
\hline & matrix & at. $\%$ & 50.9 & 20.8 & 19.9 & 3.3 & 1.9 & 1.6 & 1.7 & & \\
\hline \multirow{2}{*}{ B } & Al-rich oxide & wt. $\%$ & 1.1 & 1.2 & 0.7 & \multirow{2}{*}{ - } & \multirow{2}{*}{ - } & 9.7 & 44.1 & \multirow[b]{2}{*}{ - } & 43.2 \\
\hline & film & at. $\%$ & 0.4 & 0.5 & 0.3 & & & 4.4 & 35.6 & & 58.8 \\
\hline \multirow{2}{*}{$\mathrm{C}$} & Al -rich & wt. $\%$ & 10.7 & 5.4 & 4.1 & 5.0 & \multirow{2}{*}{ - } & 10.8 & 31.7 & \multirow[t]{2}{*}{ - } & 32.3 \\
\hline & oxide particle & at. $\%$ & 4.8 & 2.7 & 1.8 & 1.4 & & 5.9 & 30.7 & & 52.7 \\
\hline \multirow{2}{*}{$\mathrm{D}$} & Ti-rich & wt. $\%$ & 1.8 & 0.7 & 0,7 & 5.0 & \multirow[b]{2}{*}{ - } & 74.2 & 0,6 & 13,4 & 3.4 \\
\hline & $\begin{array}{l}\text { nitride } \\
\text { particle }\end{array}$ & at. $\%$ & 1.1 & 0.5 & 0.5 & 1.9 & & 54.3 & 0.8 & 33.5 & 7.4 \\
\hline
\end{tabular}




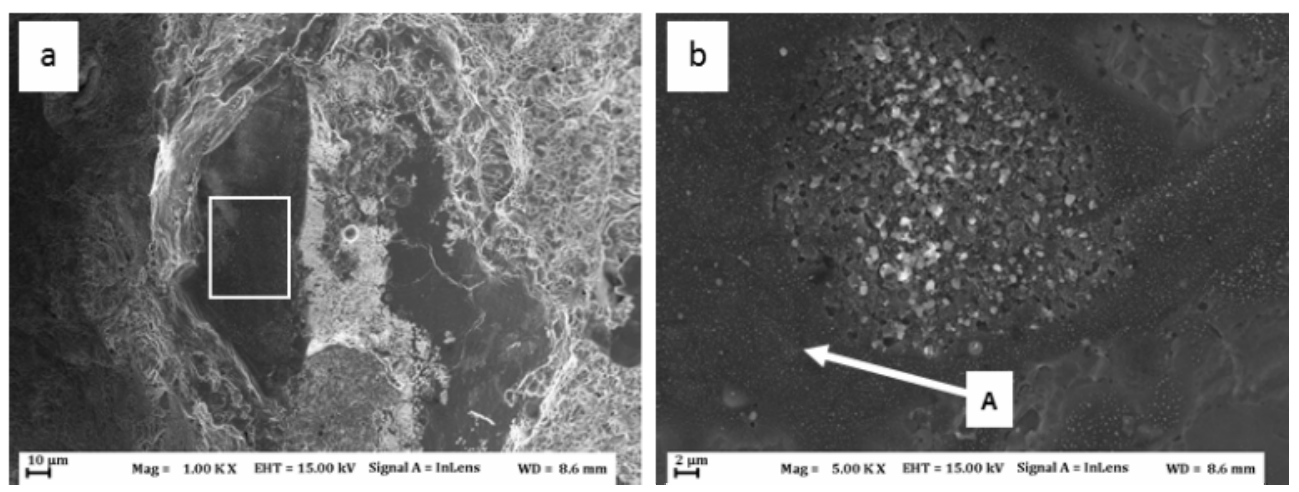

Fig.6. (a) Contour region on the fracture surface of a CVN test sample produced during cycle 14. (b) Higher magnification of denoted region showing oxide covered area. Composition in point $\mathrm{A}$ is almost identical to point $\mathrm{B}$ in Fig. $5 \mathrm{~b}$.

Figure 7 shows the fracture surface in the hatching region of a sample produced from virgin powder. Generally, it consists of fairly equiaxed dimples, indicating ductile failure occurring through microvoid coalescence. Residual porosity, TiN and oxide particles, acting as micro-void nucleation sites were occasionally observed inside the dimples. In Figure 8, the corresponding images from a sample produced from recycled powder show presence of aluminum-rich oxide clusters (denoted area in Figure 8a) sizing up to around $50 \mu \mathrm{m}$. It is realized that the size and shape of the individual oxide particulates are very similar to the particulates observed on the recycled powder surface (Figure $3 b$ ). However, whether these particles are directly transferred from the powder feedstock or rather re-nucleated and clustered together in the melt pool has to be further elaborated. As already mentioned, weak bonding between oxide and metal and also different elastic properties may result in de-bonding and subsequent coalescence of the voids formed under tensile loading. Even though considerable amounts of defects were present in these samples, a major part of the fracture surfaces has dimple character. This shows that a considerable amount of plastic deformation took place during fracture, indicating an overall ductile fracture in a large portion of the sample. Anyhow, it is well known that that presence of agglomerates of non-metallic particles can have a significant negative effect on fatigue properties. Smaller sized agglomerates, similar to those observed in the hatch regions, may act as crack initiation sites in the high to very high cycle regime [11], whereas larger sized inclusions (preferentially observed close to the contour region) has been reported to be the main cause for fatigue life scattering in the low cycle regime [12]. Therefore, the larger amount of mainly oxide-containing defects in the samples produced from recycled powder shows that powder recycling may have a negative effect on the cleanliness and therefore also on the structural integrity of EBM processed Alloy 718, especially under dynamic loading. Hence, further research is needed to increase the knowledge about imperfections in AM built components, concerning both defect formation and their effects at different loading conditions, preferably using more sophisticated techniques such as fracture toughness and/or fatigue testing. 

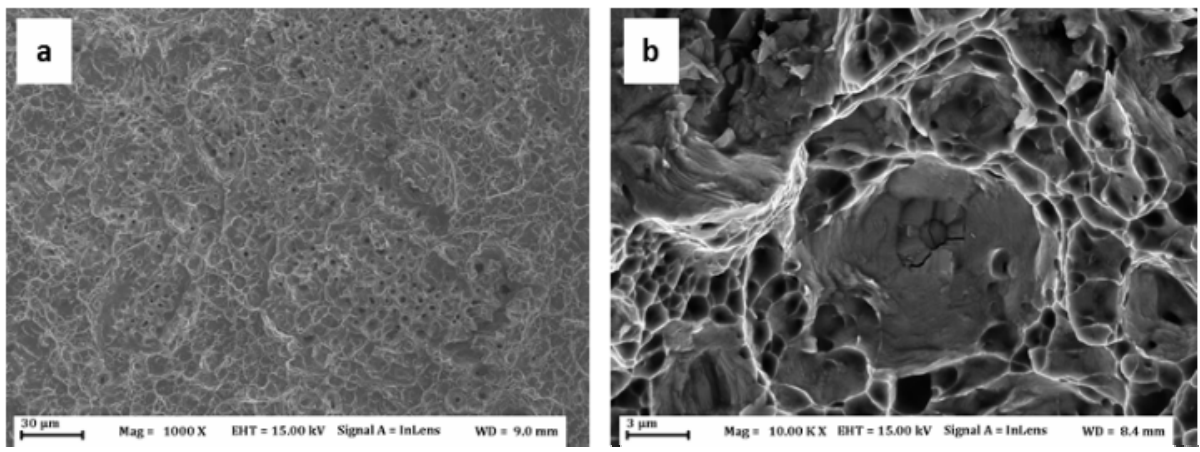

Fig.7. Hatching region on the fracture surface of a CVN test sample produced from virgin powder.
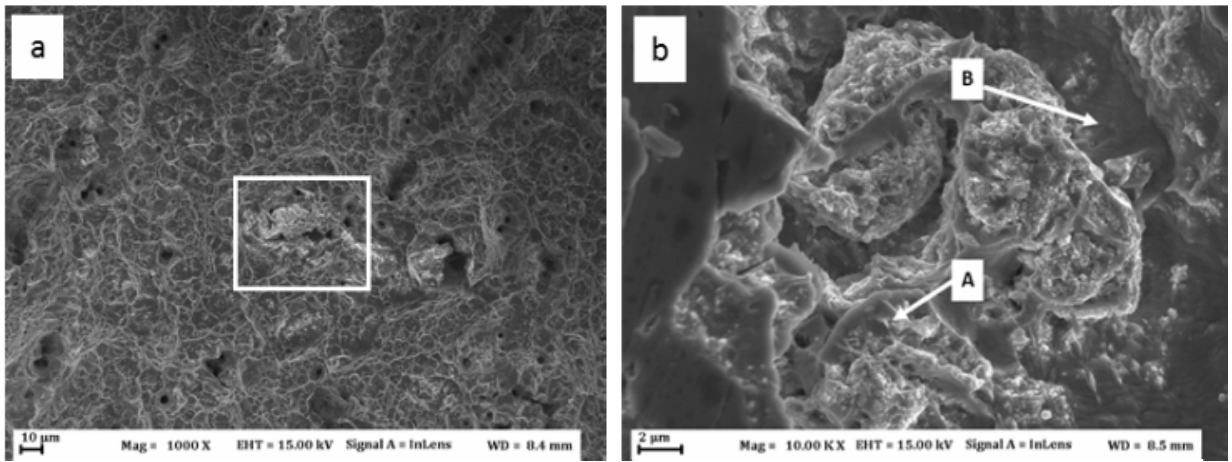

Fig.8. (a) Hatching region on the fracture surface of a test sample produced during cycle 14. (b) Higher magnification of denoted region showing aluminum rich oxide cluster. Corresponding EDX analysis data are presented in Table 4.

Tab.4. EDX analysis data from the areas in Fig.8b.

\begin{tabular}{|c|c|c|c|c|c|c|c|c|c|c|}
\hline \multirow{2}{*}{ Location } & \multirow{2}{*}{ Structure } & \multicolumn{9}{|c|}{ Chemical composition, } \\
\cline { 3 - 12 } & & & $\mathrm{Ni}$ & $\mathrm{Cr}$ & $\mathrm{Fe}$ & $\mathrm{Nb}$ & $\mathrm{Mo}$ & $\mathrm{Ti}$ & $\mathrm{Al}$ & $\mathrm{O}$ \\
\hline \multirow{2}{*}{$\mathrm{A}$} & Aluminium-rich & wt.\% & 19.4 & 8.5 & 7.9 & 3.4 & 2.1 & 2.1 & 25.5 & 31.2 \\
& oxide & at.\% & 9.1 & 4.5 & 3.9 & 1.0 & 0.6 & 1.2 & 26.1 & 53.7 \\
\hline \multirow{2}{*}{$\mathrm{B}$} & \multirow{2}{*}{ Gamma matrix } & wt.\% & 51.8 & 19.4 & 19.4 & 4.7 & 2.8 & 0.9 & 1.0 & - \\
& & at.\% & 50.7 & 21.4 & 20.0 & 2.9 & 1.7 & 1.1 & 2.1 & - \\
\hline
\end{tabular}

\section{CONCLUSIONS}

Fracture surface analysis of EBM processed Alloy 718 Charpy impact test bars produced from virgin and multi-cycle re-used powder was performed to study the effect of process induced powder degradation on defect formation and fracture behavior. The findings can be summarized as follows:

- A considerable amount of defects of varying type and size was present in samples produced from both virgin and recycled powder. 
- A large heterogeneity in terms of fracture features was observed across the fracture surfaces, with larger sized defects being preferentially located to areas close to or within the contour region.

- A large part of the areas close to or within the contour region showed presence of an intergranular type of fracture along weak interfaces originating from insufficient melting and/or presence of Al-rich oxide films and non-metallic inclusions. The main fracture mode in the hatch region was a moderately ductile dimple fracture.

- The areas covered by oxide films were significantly larger in the samples produced from recycled powder as compared to the samples produced from virgin powder.

- Al-rich oxide particle clusters in the hatching region were exclusively found in components produced from recycled powder.

\section{Acknowledgement}

The authors would like to acknowledge SIP LIGHTer and the Swedish Innovation Agency Vinnova as well as AoA Production at Chalmers for financial support. The authors express appreciation to Jonas Olsson at Production Technology Center, Trollhättan, Sweden for providing the samples.

\section{REFERENCES}

[1] Strondl, A., Palm, M., Gnauk, J., Frommeyer, G.: Mater. Sci. Technol., vol. 27, 2011, no. 5 , p. 876

[2] Chlebus, E., Gruber, K., Kuznicka, B., Kurzac, J., Kurzynowski, T.: Mater. Sci. Eng. A, vol. 639, 2015, p. 647

[3] Ma, X., Duan, Z., Shi, H., Murai, R., Yanagisawa, E.: J. Zhejiang Univ. A, vol. 11, 2010, no. 10, p. 727

[4] Ardila, LC., Garciandia, F., González-Díaz, JB., Álvarez, P., Echeverria, A., Petite, MM. Deffley, R., Ochoa, J.: Phys. Procedia C, vol. 56, 2014, p. 99

[5] Dehoff, RR., Kirka, MM., Sames, WJ., Bilheux, H., Tremsin, AS., Lowe, LE., Babu, SS.: Mater. Sci. Technol., vol. 31, 2015, no. 8, p. 931

[6] Denda, T., Bretz, PL., Tien, JK.: Metall. Trans. A, vol. 23, 1992, no. 2, p. 519

[7] Riemer, A., Leuders, S., Thöne, M., Richard, HA., Tröster, T., Niendorf, T.: Eng. Fract. Mech., vol. 120, 2014, p. 15

[8] Deng, D., Moverare, J., Peng, RL., Söderberg, H.: Mater. Sci. Eng. A, vol. 693, 2017, p. 151

[9] Sames, V., William James: Additive manufacturing of Inconel 718 using electron beam melting: Processing, post-processing, \& mechanical properties, 2015, p. 340

[10] Gruber, H., Hryha, E., Nyborg, L.: Alloy 718 powder degradation during multi-cycle EBM processing. In manuscript

[11] Krewerth, D., Lippmann, T., Weidner, A., Biermann, H.: Int. J. Fatigue, vol. 84, 2016, p. 40

[12] Matz, JE., Eagar, TW.: Metall. Mater. Trans. A, vol. 33, 2002, no. 8, p. 2559 